\title{
Упорядочение церковно-административного статуса митрополий на Халкидонском соборе на примере тяжбы митрополитов Тира и Берита
}

\author{
М.В. Грацианский \\ Московский государственный университет имени М.В. Ломоносова, \\ РФ, 119192, г. Москва, Ломоносовский проспект, д. 27, корп. 4, исторический факультет \\ E-mail: gratsianskiy@mail.ru
}

\begin{abstract}
Аннотация. Статья посвящена исследованию роли императора в определении церковноадминистративного статуса городов-митрополий. В качестве примера автором берется пример тяжбы между епископами городов Тира и Берита римской провинции Первая Финикия в ходе IV Вселенского собора в Халкидоне (451 г.). В то время как епископ Тира был правящим митрополитом провинции, город Берит (совр. Бейрут) получил в 449 или в 450 г. статус митрополии на основании императорского пожалования. Епископ новой митрополии Евстафий взял под свое управление церкви шести городов севера провинции, что тирский митрополит Фотий посчитал неканоническим шагом и обратился с апелляцией к императору Маркиану (450-457). Последний передал это дело на рассмотрение Собора, повелев, чтобы спор был разрешен на основании церковных канонов, а не государственных законов. Как следствие, присвоение епископом новой митрополии прав рукоположения в городах провинции было признано неканоническим, и беритскому епископу было указано довольствоваться лишь титулом митрополита, в то время как церковное управление оставалось в руках митрополита Тира гражданской столицы провинции. Пример тяжбы между Тиром и Беритом наглядно иллюстрирует взаимодействие гражданской (императорской) и церковной юрисдикций в решении церковноадминистративных дел и выявляет ведущую роль императора. Этот пример также является важным как иллюстрация механизма того, как на основе конкретных дел вырабатывались общеобязательные церковные каноны.
\end{abstract}

Ключевые слова: Поздняя античность, Халкидонский собор, Тир, Берит, Фотий Тирский, Евстафий Беритский, император Маркиан, митрополии, церковное управление, каноны.

Для цитирования: Грацианский М.В. 2020. Упорядочение церковно-административного статуса митрополий на Халкидонском соборе на примере тяжбы митрополитов Тира и Берита. Via in tempore. История. Политология, 47 (3): 505-517. DOI 10.18413/2687-0967-2020-47-3-505-517.

\section{Status regulation of metropoleis in regard to the ecclesiastical administration during the council of Chalcedon: the case of the litigation between the metropolitans of Tyre and Berytus}

\author{
Mikhail V. Gratsianskiy \\ Lomonosov Moscow State University, \\ 27/4 Lomonosovskiy ave., Faculty of History, Moscow, 119192, Russia \\ E-mail: gratsianskiy@mail.ru
}

\begin{abstract}
The article is devoted to the study of the role of the emperor in determining the churchadministrative status of metropoleis. As an example, the author takes a litigation between the bishops of Tyre and Berytus from the Roman province Phoenicia Prima during the $4^{\text {th }}$ Ecumenical Council in Chalcedon (451). While the bishop of Tyre was the ruling metropolitan of the province, the city of Berytus (modern Beirut) received in 449 or 450 the metropolitan status through the imperial decree. The
\end{abstract}


bishop of the new metropolis, Eustathius, took control of the churches of six cities in the north of the province, which Metropolitan Photius of Tyre considered to be an uncanonical step and subsequently appealed to the emperor Marcian (450-457). The latter referred the matter to the Council, ordering that the dispute be resolved on the basis of church canons, and not state laws. As a result, the usurpation by the bishop of a newly created metropolis of ordination rights in the provincial cities was recognized noncanonical and the bishop of Berytus was instructed to be content only with the title of Metropolitan, while church administration remained in the hands of the Metropolitan of Tyre, the latter being the capital of the civil province. The example of litigation between Tyre and Berytus clearly illustrates the interaction of civil (imperial) and church jurisdictions in regulating the affairs of ecclesiastical administration and reveals at the same time the leading role of the emperor. This example is also important as an illustration of the mechanism of how generally binding church canons evolved from concrete cases.

Key words: Late Antiquity, the Council of Chalcedon, Tyre, Berytus, Photius of Tyre, Eustathius of Berytus, emperor Marcian, metropoleis, ecclesiastical administration, canons.

For citation: Gratsianskiy M.V. 2020. Status regulation of metropoleis in regard to the ecclesiastical administration during the council of Chalcedon: the case of the litigation between the metropolitans of Tyre and Berytus. Via in tempore. History and political science, 47 (3): 505-517 (in Russian). DOI 10.18413/2687-0967-2020-47-3-505-517.

Одним из важнейших направлений изучения истории церкви в Римской империи периода поздней античности является изучение правовых и процедурных условий, а также рамок, в пределах которых римский император осуществлял управление церковными делами. Кроме того, важным и более частным вопросом является роль императора в разработке канонической традиции. Одним из наиболее значимых источников данных по этой теме являются соборные акты IV-V вв., прежде всего, акты III и IV Вселенских соборов, состоявшихся в Эфесе в 431 и в Халкидоне в 451 г. При этом акты Халкидонского собора оказываются в значительной мере более ценным материалом в силу гораздо большей вовлеченности государственной власти его в проведение.

Ввиду этого представляется необходимым дальнейший анализ сведений, содержащихся в соборных актах и проливающих свет на указанные нами темы. Эти сведения почерпаются из протоколов отдельных «деяний» соборов, на которых рассматривались те или иные дела. В настоящей работе мы ставим задачу изучить обстоятельства рассмотрения на IV Вселенском соборе в Халкидоне иска епископа Тира Фотия против епископа Берита Евстафия, поданного императору Маркиану (450-457) и рассмотренного на одном из заседаний Халкидонского собора [Троицкий, 1959, с. 255-257; Jones, 1964, p. 883; Millar, 2012, p. 65-84; Leuenberger-Wenger, 2019, p. 305-310]. Протокол соборного заседания, состоявшегося 20 октября 451 г., представлен в сохранившихся актах Халкидонского собора в виде последнего, девятнадцатого «деяния» [Schwartz, 1935, p. 101-110] ${ }^{38}$. Помимо выяснения процедуры рассмотрения данного дела и принятия по нему решения, нашей задачей является показать, какова была роль императора в этом деле и как последнее повлияло на формулировку некоторых канонов, принятых на Халкидонском соборе.

Халкидонский собор был созван императором Маркианом для рассмотрения многочисленных дел, поданных на имя, прежде всего, самого императора, а также римского папы Льва I (440-461). Собор был инициирован императором с целью пересмотра итогов Эфесского собора 449 г., недовольство результатами которого наблюдалось в весьма широких церковных и политических кругах как Востока, так и Запада. В силу этого в задачу Маркиана входил пересмотр и частных решений, бывших результатами церковной политики предшествующего царствования, направленной на утверждение авторитета александрийской кафедры и александрийского богословия в пределах Восточной Римской империи. Одним из таких частных решений Феодосия II (408-450) было возвышение города

\footnotetext{
${ }^{38}$ В сохранившейся латинской версии актов Халкидонского собора данное деяние отсутствует.
} 
Берита до статуса митрополии как способ, в том числе, вознаградить местного епископа за его деятельность в качестве союзника Кирилла, а затем Диоскора Александрийского в ряде эпизодов, связанных с противоборством Антиохийской и Александрийской кафедр [Rammelt, 2008, p. 154-180; Вселенские соборы, 2005, с. 78-81].

Повестка соборных заседаний была сформирована императором на основании многочисленных челобитных, которые подавались Маркиану с того момента, как им было объявлено о проведении собора. Последний был призван, среди прочего, пересмотреть дело низложенного Флавиана Константинопольского и дать оценку соборам 448-449 гг., поводом к проведению которых послужило дело константинопольского архимандрита Евтиха [Schwartz, 1921, p. 231-234; Schwartz, 1929, p. 1-93; Draguet, 1931, p. 441-457; May, 1989, p. 9-53; Bevan, 2008, p. 617-657; Vranić, 2008, p. 208-221]. Дело Евтиха, казалось, было окончательно закрыто на Эфесском соборе 449 г. под председательством Диоскора Александрийского, завершившемся оправданием Евтиха и осуждением Флавиана Константинопольского, однако многочисленные протесты с Востока и с Запада, а также смена императора в Константинополе привели к тому, что церковная политика в преддверии Халкидонского собора оказалась развернутой на 180 градусов.

Одним из частных сюжетов, по которому Маркиан предпринял пересмотр решения, принятого Феодосием II (408-450), как раз и был разбор спора между Фотием Тирским и Евстафием Беритским [Van Roey, 1967, p. 23; Windau, 2002, p. 250; Грацианский, 2008, c. 302-303]. Предметом спора было дарование императором Феодосием II городу Бериту привилегий митрополии ${ }^{39}$. Отрывок соответствующего указа сохранился в составе Кодекса Юстиниана. Приведем здесь его перевод: «Императоры-августы Феодосий и Валентиниан префекту претория Гормизду. По многим и справедливым причинам мы определяем, что Бериту, уже увенчанному собственными добродетелями, надлежит быть украшенным именем и достоинством митрополии (metropolitano nomine ac dignitate). Итак, пусть он также имеет достоинство митрополии (metropolitanam dignitatem). У Тира ничего из его прав не изымается: пусть будет он матерью провинции (mater provinciae) благодаря благодеянию наших предков, Берит же - благодаря нашему, и пусть оба наслаждаются сходным достоинством (dignitate simili)» [Krueger, 1954, p. 434].

Возведение города в статус митрополии не было чем-то необычайным. В контексте церковного управления оно тем не менее влекло за собой зачастую и перераспределение церковно-административных полномочий, вызывая тем самым ожесточенные споры. На самом Халкидонском соборе, помимо спора Тира и Берита, рассматривался также аналогичный спор Никомидии и Никеи, имеющих статус митрополий в пределах провинции Вифиния [Schwartz, 1935, p. 56-62]. Следует отметить и более ранний прецедент спора между Вьенной и Арлем, разрешенный в 398 г. на Туринском соборе в том смысле, что тот город, который докажет, что он является митрополией, получит в провинции первенство (totius prouinciae honorem primatus) [Munier, 1963, p. 56; Норкин, 2019, с. 54-57].

Очевидным образом и в данном случае дело не закончилось лишь повышением статуса города: как явствует из показаний Фотия Тирского, Евстафий Беритский взял под свое непосредственное церковное управление, т. е. начал совершать хиротонии в нескольких городах провинции Первой Финикии - Библосе, Ботрисе, Триполи, Орфосиаде, Арках и Антараде (совр. Тартус) [Schwartz, 1935, 106.5-6; Jones, 1971, p. 544]. Более того, из епископов упомянутых городов он, как представляется, составил собственный собор [Schwartz, 1935, 104.24-31]. При этом права тирского митрополита представлялись незыблемыми, так как основывались на древнем положении Тира как митрополии Финикии ${ }^{40}$ и на устойчивой практике совершения рукоположений в провинции епископом Тирским ${ }^{41}$.

${ }^{39}$ О Берите в составе Римской империи см.: [Jones, 1971, p. 226-294, 544; Jones Hall, p. 2001-2002; Butcher, 2003, p. 79-121; Jones Hall, 2004].

40 О понятии «митрополия» в римскую эпоху, связанном с императорским культом и возникновением соответствующей сакральной «инфраструктуры»: [Puech, 2004]. О положении Тира как 
Апелляция Фотия, поданная Маркиану, важна для понимания того, как тирский епископ видел процедуру рассмотрения его дела императором. Приведем здесь ее полный перевод:

«Владыкам земли, и моря, и людей всякого народа и рода Флавиям Валентиниану и Маркиану, вечным победителям-августам, прошение и мольба от Фотия, епископа митрополии тирцев Вашей Первой Финикии. Все, кто желают [нечто] обрести согласно своему желанию, сделают это не иначе как если припав к Вашим стопам, смогут добиться какоголибо плода того, чего чают, но только если право на стороне их челобитий. Потому и я прибег к подобным просьбам, убедив себя в том, что не разминусь с чаемой надеждой, если за меня будет бороться право. Какова причина моих прошений, будет указано в кратком слове. Для святейшей Церкви тирцев с древних и незапамятных времен были определены святыми канонами видные права в деле церковного управления и хиротоний ${ }^{42}$. Эти права Евстафий, честнейший епископ города беритцев, возымев по случаю намерение

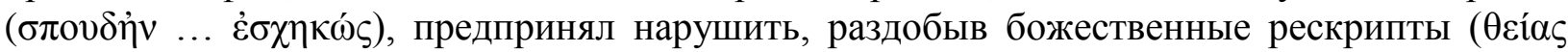

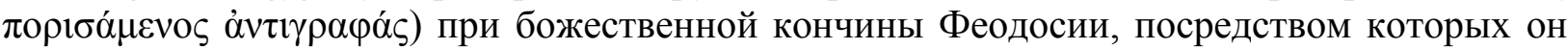
возжелал, присвоив себе хиротонии в видных городах, перенести на себя некоторые права вышеуказанной церкви. Упомянутый епископ изъявил в переписывании церковных прав такую настойчивость, что даже приготовил и направил мне соборное послание, угрожая низложением, если я не подпишу эту хартию. Каковую я, не по пожеланию, но из страха перед заключенной в ней угрозой, и подписал, обозначив подписью совершенное надо мной принуждение.

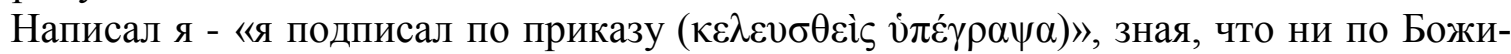
им законам, ни по законам божественных [императоров] ничто для меня этим не предре-

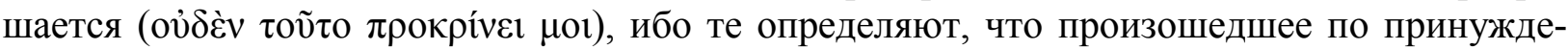
нию не имеет никакой силы ${ }^{43}$. При Вашем же благочестии все люди хорошо знают по

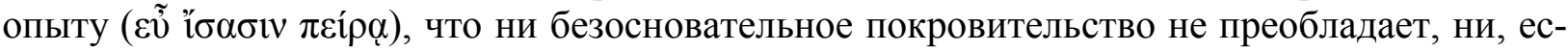
ли кто захочет добиться чего-либо не признанного древностью, не сможет [сделать этого]

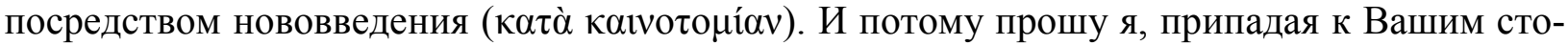
пам, чтобы Ваша небесная держава повелела оставить неповрежденным всё, что божественными канонами было определено для вышеуказанной святейшей церкви. Если же, будь то упомянутым [лицом] или кем-нибудь другим, нечто было предпринято вопреки

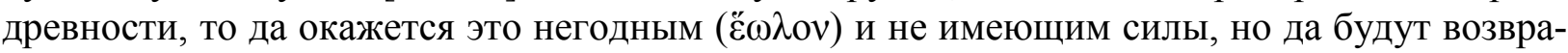
щены права святейшей церкви Тира неповрежденными, а всё, что было предоставлено вышеупомянутому [лицу] посредством узурпации, да будет отменено, хотя бы оно и содержалось в божественных грамотах или в решениях каких бы то ни было высших судов

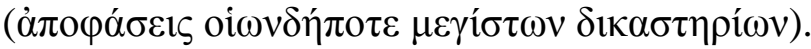

А если ради нарушения древности и божественных канонов было некое согласие каких-то святейших епископов, то да не имеет оно никакой силы, поскольку не было для меня никакого предрешения ${ }^{44}$ из-за того, что я подписался указанным образом под соборным посланием. И да будет направлено об этом Ваше божественное и чтимое прагматиче-

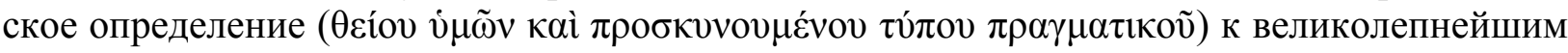

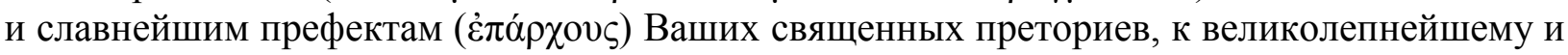

древней митрополии, имевшей этот титул, по крайней мере, со времен Домициана (81-96), и столицы провинции с конца II в.: [Aliquot, 2011; Millar, 2012, p. 66-83; Vitale, 2013, p. 64-73].

${ }^{41} \mathrm{CM}$. о роли провинциальных столиц как религиозных центров в дохристианский и в христианский период: [Haensch, 1997; Haensch, 2006].

42 Под канонами Фотий очевидным образом имеет в виду либо издревле сложившуюся практику, либо какие-то каноны, принятые местными соборами финикийского или антиохийского уровня.

43 Очевидным образом Фотий обыгрывает здесь от обратного римский юридический принцип «volenti non fit iniuria».

44 Здесь идет речь о юридическом понятии «преюдиции» или «предрешения» (praeiudicium,

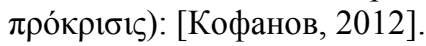




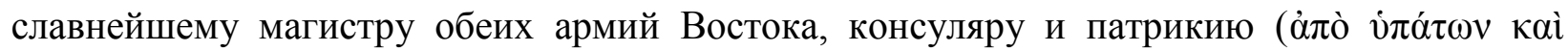
$\left.\pi \alpha \tau \operatorname{cí}^{\prime} 10 v\right)$ Зинону, а также к великолепнейшему и славнейшему магистру Ваших боже-

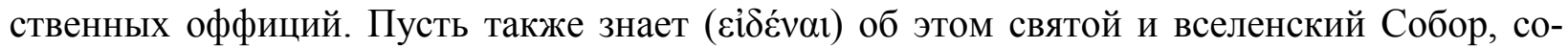
бранный во граде халкидонцев по благодати Божьей и Вашему повелению, дабы ничто не могло произойти вопреки повелениям Вашего благочестия: ведь священные права никоим образом не должны приуменьшаться из-за небрежения предстоятелей. Добившись этого, буду воздавать положенные молитвы за Вашу вечную державу» [Schwartz, 1935, 104.10105.13; Millar, 2012, p. 78-79].

Как видно из челобитной, Фотий не предусматривал для пересмотра этого дела проведения какого-либо расследования, проводимого церковными органами. Дело, начатое императором, даровавшим статус митрополии Бериту, должно было быть пересмотрено самим же императором в рамках светского делопроизводства, а именно путем издания прагматической санкции на имя высших чиновников, в сфере компетенции которых находилась префектура Восток. При этом называются как гражданские чиновники, так и военный ${ }^{45}$, в то время как Вселенский собор, по мнению Фотия, следовало всего лишь поставить в известность об императорском решении.

Между тем дело Фотия находилось исключительно в плоскости церковноадминистративных отношений. Тирский епископ не просит у Маркиана отменить решение Феодосия II о возвышении Берита до положения митрополии: он просит лишь устранить церковно-административные последствия этого решения, а именно раскол единой провинции Первая Финикия на две церковные области - митрополии Тирскую и Беритскую со своими особыми границами.

Строго говоря, то, что было предпринято Евстафием Беритским, не основывалось на строгом прочтении указа Феодосия II: этот указ в его сохранившейся форме не содержит распоряжений относительно статуса епископа Берита в его новом качестве епископа митрополии. По-видимому, Евстафий сам истолковал издание указа как возможность присвоить себе рукоположения епископов в шести упомянутых выше городах, которые таким образом составили собор Беритской митрополии ${ }^{46}$.

Именно последний факт вызвал вскоре церковно-правовую коллизию, когда Фотий, несмотря на подписанную им синодику, фиксирующую новое церковноадминистративное положение в Первой Финикии, предпринял рукоположения в присвоенных себе Евстафием городах, в ответ на что последний низложил их, низведя в сан пресвитера. Дело о поставлении Фотием епископов и их низложении Евстафием было доведено до патриарха Константинопольского и в 450 г. рассмотрено в столице «пребываю-

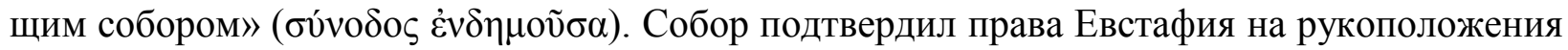
в шести городах, причем под решениями собора подписался и Максим Антиохийский, рукоположенный в Константинополе после низложения на Эфесском соборе его предшественника Домна II [Грацианский, 2007] и всё еще находившийся в столице [Schwartz, 1935, 106.5-19]. Собор постановил подвергнуть Фотия отлучению от общения [Schwartz, $1935,106.28-31]^{47}$.

45 Префекты указаны во множественном числе и потому следует предполагать, что префект Иллирика (второй префект в составе Восточной Римской империи) тоже должен был получить соответствующий эдикт, даже несмотря на то, что префектура Восток не относилась к его компетенции. Не исключено, что имелся в виду и префект Константинополя, хотя это менее очевидно.

46 Отбор именно этих городов и тот факт, что они очевидным образом не протестовали против их включения в новую митрополию, по-видимому, обусловлен тем, что они традиционно находились в тесной связи с Беритом или в некоей зависимости от последнего. Географически они были расположены ближе к Бериту, чем к Тиру.

${ }^{47}$ Нам кажется не совсем точным предположение Ф. Миллара [Millar, 2012, p. 80] о том, что именно Константинопольский собор разделил Первую Финикию на два митрополичьих округа. Для того, чтобы собор мог принять это решение, в апелляции к собору, отправленной Евстафием, должно было уже быть зафиксировано согласие епископов упомянутых шести городов о вхождении в собор новой митрополии. Именно в таком случае 
Именно в такой ситуации, имея против себя указ Феодосия II, решение собора новосозданной Беритской митрополии и «пребывающего собора» в Константинополе, поддержанное патриархом Антиохийским, Фотий обратился к императору с тем, чтобы отменить все указанные церковно-административные решения и вернуть тирской кафедре ее прежнее положение. Представ перед участниками Вселенского собора и председательствующими на нем императорскими чиновниками ${ }^{48}$, Фотий обратился к последним со

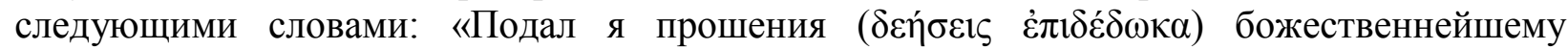
$(\theta \varepsilon 10 \tau \alpha ́ \tau \omega)$ и христолюбивому императору, а он и приказал Вашему великолепию

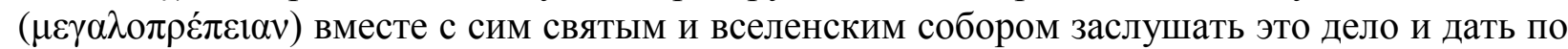
нему определение ( $\tau \dot{\pi} \pi \mathrm{v})$. Потому прошу я, чтобы были зачитаны мои прошения и было воздано мне по справедливости» [Schwartz, 1935, 103.32-35]. На это Фотий получает следующий ответ судей: «Поскольку наш божественный император, получив обращение от Фотия, честнейшего епископа митрополии тирцев, приказал, чтобы то, что касается его и

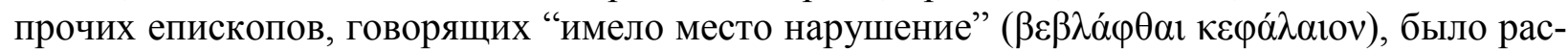
смотрено в вашем присутствии на святейшем соборе, то пусть будут зачитаны прошения благочестивейшего епископа Фотия» [Schwartz, 1935, 104.3-7].

После того как была зачитана челобитная Фотия, между сторонами состоялся примечательный диалог, целью которого было выяснение сановниками у обеих сторон, в какой юрисдикции они желают рассматривать дело: в гражданской или в церковной. Прежде всего, Евстафий Беритский задал вопрос, намерен ли Фотий следовать канонической

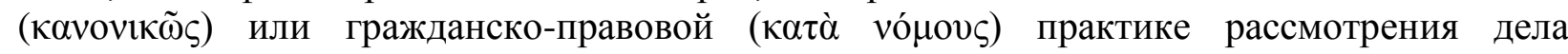
[Schwartz, 1935, 105.16-17]. Фотий на это заявляет, что оставляет этот вопрос на усмотрение присутствующих чиновников и епископов [Schwartz, 1935, 105.20]. В результате чиновники провозглашают, что, согласно представлению императора, это дело будет рас-

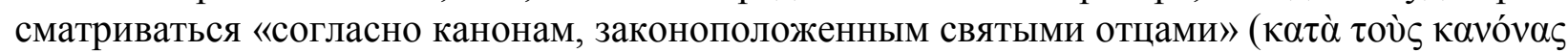

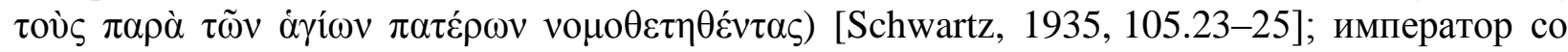
своей стороны приостанавливал действие определения императорской санкции, полученной Евстафием от Феодосия II. По этой причине архонты потребовали от епископов собора озвучить относящиеся к сути дела каноны [Schwartz, 1935, 105.25-27].

Поскольку привлечение канонов в качестве правовой основы для рассмотрения дела требовало привлечения к процессу членов собора, сановники обратились к последним с тем же вопросом: следует ли рассматривать дело по канонам или всё же на основании им-

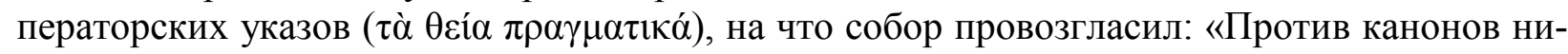
какой указ да не имеет силы; пусть преобладают каноны отцов!» [Schwartz, 1935, 105.36]. Не отвергнув такую постановку вопроса, сенаторы потребовали от епископов высказаться, «позволено ли согласно божественному [т. е., императорскому - М.Г.] указу другим епископам присваивать права чужой церкви» [Schwartz, 1935, 105.38-40]. Собор решительно

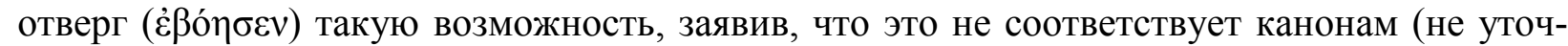
няя, впрочем, каким именно).

Здесь следует еще раз подчеркнуть, что в силу того, что жалоба Фотия была подана императору, именно в компетенции последнего оказывалось ведение этого дела и именно им была определена та регламентирующая сфера, в рамках которой оно будет рассматри-

рукоположения Фотия могли быть признаны незаконными, а сам он подвергнут отлучению. Таким образом,

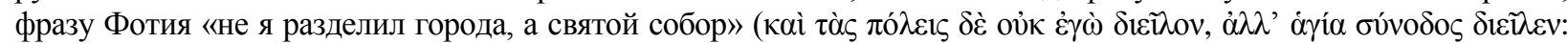
Schwartz, 1935, 106.23-24), следует понимать так, что столичная «эндимуса» лишь зафиксировала уже произошедшее разделение. Также Ф. Миллар не прав, принимая отлучение Фотия от общения

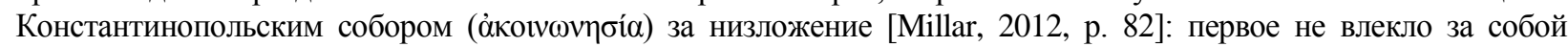
второго автоматически. Кроме того, следует отметить, что на Халкидоне Фотий выступает с самого начала как действующий митрополит Тира, хотя его спор с Евстафием был рассмотрен далеко не сразу.

48 О председательстве на Халкидонском соборе: [Chrysos, 1979; Price, 2009, p. 247-248; Пашков, 2018, с. 31-35; Грацианский, 2019]. Краткая характеристика процедурной стороны рассмотрения дела: [Leuenberger-Wenger, 2019, p. 304]. 
ваться - каноны ${ }^{49}$. Тем самым Маркианом было признано, что дело относится к церковной юрисдикции и потому оно, на основании ряда императорских законов, должно было рассматриваться епископами [Троицкий, 1961]. Тем не менее как процедура рассмотрения обстоятельств дела, так и вынесение окончательного приговора оказывались в руках уполномоченных императором судей из числа высших сановников империи, поскольку именно они председательствовали на Соборе.

Вследствие сделанного отцами Собора заявления сановники далее выяснили, имело ли место нарушение канонов, а именно: какие города забрал себе Евстафий Беритский и совершал ли он в них рукоположения. Не отрицая таковых фактов, Евстафий привел в свое оправдание уже упомянутое решение, полученное в Константинополе и заверенное в том числе Максимом Антиохийским. Согласно его словам, возвышение Берита в статус митрополии было произведено императором отнюдь не по просьбе епископа, а разделение городов между двумя митрополитами было закреплено решением Константинопольского coбopa [Schwartz, 1935, 106.20-24].

Естественным образом, сенаторы после этого обратились к Анатолию Константинопольскому за разъяснениями, имел ли право «пребывающий собор» Константинополя рассматривать подобное дело в отсутствии обвиняемого. Более того, сенаторы запросили,

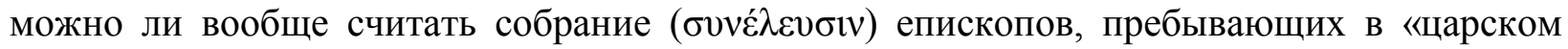
граде», собором [Schwartz, 1935, 106.37-41]. И если ответ Анатолия в том смысле, что собрание епископов в Константинополе традиционно рассматривает поступающие на рассмотрение дела и выносит по ним решения, был принят чиновниками без возражений, то факт суда над Фотием в его отсутствие был признан не отвечающим правовым нормам [Schwartz, 1935, 107.1-16] ${ }^{50}$.

В свою очередь, Фотий еще раз потребовал соблюдения в его случае канонов, что должно было выразиться в признании законными совершенных им рукоположений и возвращении ему отторгнутых Евстафием церквей. После того как отцы собора признали та-

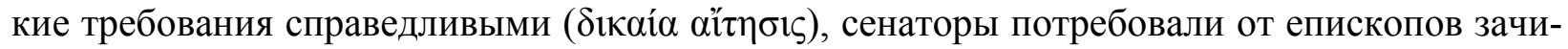
тать им регламентирующие эту ситуацию каноны. Епископами был представлен 4-й канон Никейского собора: «Епископу, конечно же, надлежит поставляться всеми [епископами] епархии. Если же подобное будет затруднительно либо по причине срочной нужды, либо из-за отдаленности пути, то когда из всех соберутся в одном месте трое и достигнут единогласия, в то время как отсутствующие дадут согласие посредством писем, тогда [надлежит] совершиться рукоположению. Утверждение же происходящему [надлежит] давать в каждой епархии митрополиту» [Schwartz, 1935, 107.25-30].

Как следствие, сенаторы поинтересовались, соблюдался ли этот канон при рукоположениях, совершаемых Евстафием, на что последний ответил утвердительно: рукоположения совершались им в присутствии тех епископов, которые признавали его митрополитом. Подтвердив соблюдение им канона, Евстафий далее признал, что император в данной ситуации может решить так, как ему будет угодно: «Теперь же благочестивейший император может приказать, что он хочет» [Schwartz, 1935, 107.34-35].

На уточняющий вопрос сенаторов к собору, должен ли быть один митрополит, имеющий власть при рукоположениях епископов в каждом городе провинции, или их может быть двое, собор ответил, что они считают ( $\dot{\alpha} \xi$ iov $\mu \varepsilon v)$, что на основании канонов митрополит один, и это, согласно взявшему слово Аттику Никопольскому, вытекает из огла-

49 Применительно к указанному периоду, по-видимому, невозможно говорить о наличии целой сферы права - права канонического. В конце концов, в распоряжении епископов было лишь крайне ограниченное количество признанных канонических определений, которыми они могли оперировать: в сущности, только определения I Вселенского собора. Эти последние уже были признаны императорами и имели силу закона: как

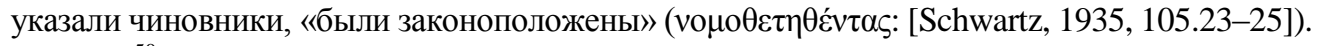

50 Показательно, что на это обстоятельство настоятельно указал митрополит Никомидийский, сам подавший императору иск об ущемлении своих митрополичьих прав в сходном случае. 
шенного канона. Кроме того, Аттик от имени прочих членов собора запросил, чтобы данное положение отныне действовало для всех епархий, а все случаи, когда епархии делились путем договоренностей или вследствие императорских санкций, были отменены

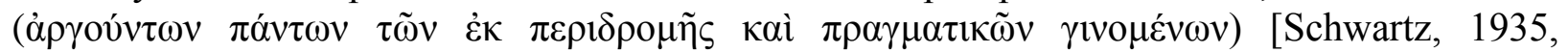
107.36-108.7]. Вслед за этим «на основании канонов 318 святых отцов, голоса и мнения всего святого собора» сановники признали Фотия имеющим власть рукополагать

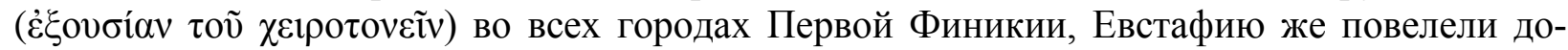
вольствоваться только титулом. Собор единогласно поддержал это решение [Schwartz, 1935, 108.8-17].

Далее были признаны законными рукоположения Фотия, а по вопросу, было ли законным низведение Евстафием рукоположенных Фотием епископов в сан пресвитеров, сенаторы призвали собор вынести решение и проголосовать за него самостоятельно [Schwartz, 1935, 108.28-19]. Из этого следует, что данный вопрос чиновники не относили к компетенции гражданских властей, тем более что по его поводу апелляции к императору не было. Соответствующее решение тем самым было озвучено первенствующими на соборе епископами: викариями папы и Анатолием Константинопольским. Прочие присоединились к нему, подавая свой голос в порядке старшинства. Сенаторы со своей стороны подтвердили решение собора [Schwartz, 1935, 108.32-109.31].

Примечательным далее является реплика Кекропия, епископа Севастопольского: «Для того чтобы ни Ваша власть не утруждалась (ко́ $\mu v \varepsilon \imath v)$, принимая прошения от каждого лица, ни мы времени не теряли ( $\mu \eta \dot{\tau \varepsilon} \dot{\eta} \mu \tilde{\alpha} \varsigma \sigma v v \tau \rho i ́ \beta \varepsilon \sigma \theta \alpha 1)$, просим, чтобы неукоснительно были упразднены выданные кому бы то ни было в нарушение канонов во всякой епар-

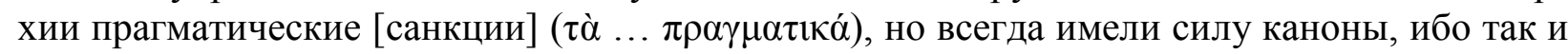
вера оберегается, и всякая церковь имеет надежность, и чтобы не было позволено никому рукополагать вопреки канонам» [Schwartz, 1935, 109.32-37].

В данном случае мы имеем запрос со стороны церкви о создании новой законодательной нормы, которая должна была получить форму канона. Сенаторы задали вопрос, согласны ли с такой постановкой вопроса отцы собора. В ответ они услышали: «Мы все говорим то же

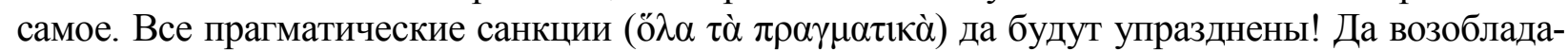

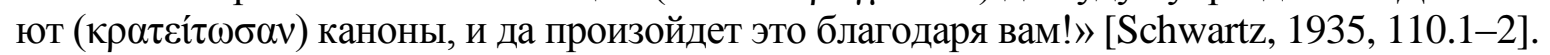

Несмотря на неоднократные заявления членов собора в ходе данного заседания о том, что каноны имеют преобладание над императорскими распоряжениями, мы не находим фиксации этого принципа в действующем на тот момент законодательстве. И сами отцы собора своей последней репликой подтверждают, что только император может законодательно утвердить принцип приоритета канонов над императорскими указами в сфере церковного управления, разрешив принятие соответствующего канона: сами епископы этого сделать не могут.

Строго говоря, епископы тем самым продемонстрировали невозможность на канонической основе разрешить спор между Фотием и Евстафием: представленное в ходе сессии каноническое основание для решения в пользу Фотия в виде 4-го никейского канона очевидным образом не вполне относилось к делу, поскольку данный канон не утверждал наличия одного митрополита в провинции. Следует подчеркнуть, что более прямо относящиеся к делу 34-е апостольское и 9-е антиохийское правила [Rhalles, Potles, 1852, vol. 2, 45; vol. 3, p. 140-141; Ohme, 1998, p. 485-509; Troianos, 2017, p. 47-56], по-видимому, не имели статуса общепризнанных канонов, причем дело Фотия и Евстафия показывает это весьма наглядно ${ }^{51}$.

51 Следует подчеркнуть стремление отцов собора выносить решения, основываясь только на канонах Никейского coбора: [Smith, 2018, p. 171-207]. В целом, конечно же, к ситуации Тира был вполне приложим 9-й канон Антиохийского собора 341 г., однако сослаться на него в Халкидоне оказалось невозможно. Очевидным образом статус Вселенского собора подразумевал ссылки только на каноны, изданные либо признанные Вселенскими соборами. По-видимому, именно в силу этого на Трулльском соборе (691-692 гг.) было принято решение возвести в статус общепризнанных каноны целого ряда поместных соборов. 
Тем самым, именно императорские чиновники утверждают принцип, согласно которому принцип единства митрополичьей власти в провинции получает преобладание над императорскими указами, относящимися к той же сфере. Сенаторы провозглашают: «Согласно решению святого собора, и во всех прочих епархиях да преобладают [определения] канонов» [Schwartz, 1935, 110.3-4]. Тем самым, именно Халкидонский собор утверждает принцип «один митрополит - одна епархия», который до того времени очевидным образом не имел универсального применения ${ }^{52}$. Это видно из целого ряда дел, рассмотренных на Халкидонском соборе, не исключая и тех, в которые был вовлечен константинопольский предстоятель ${ }^{53}$.

Именно это решение оформляется в качестве 12-го правила Халкидонского собора: «Дошло до нас, что некоторые, вопреки церковным установлениям прибегнув к властям, посредством прагматических [санкций] разделили епархию на две [части], так что от этого получилось в епархии два митрополита. Посему святой собор определил, чтобы впредь епископ не дерзал на подобное, поскольку предпринявший подобное выпадает из своего чина. Сколько бы ни было городов, которые на основании царских грамот были почтены

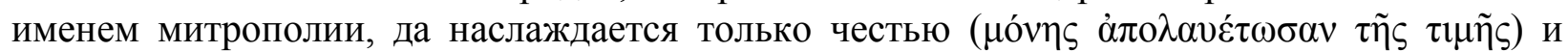
управляющий его церковью епископ, то есть истинная митрополия. сохраняет собственные права» [Schwartz, 1931, 160.25-31] ${ }^{54}$.

Тем самым, можно констатировать, что именно в ходе Халкидонского собора была канонически закреплена, а затем утверждена императором система «одна провинция один правящий митрополит» ${ }^{5}$. Очевидным образом в предшествующий период митрополиты видели эту ситуацию иначе: после получения городом на основании императорской привилегии статуса митрополии местный епископ считал возможным перераспределить провинциальные хиротонии и создать свой особый собор.

Осознавая такую возможность и стремясь предотвратить конфликты, императоры, наделяя города почетным статусом митрополии, стали подчеркивать, что митрополии столицы провинций не утратят своих прав на церковное управление ${ }^{56}$.

Таким образом, несмотря на то, что IV Вселенский собор в Халкидоне принял решение о примате канонов над императорскими законами в деле определения границ церковной юрисдикции и статуса епископов, 12-е соборное правило, по сути дела, закрепляло принцип единоначалия в управлении гражданской провинцией посредством недопущения ее раскола в церковно-административном отношении.

\section{Список литературы}

1. Вселенские соборы. 2005. М., ЦНЦ «Православная энциклопедия», 223.

2. Грацианский М.В. 2007. Домн II, еп. Антиохийский. Православная энциклопедия, т. 15, М., ЦНЦ «Православная энциклопедия», 630-632.

52 Вопреки мнению Ф. Миллара [Millar, 2012, p. 81]: The principle that there should be one metropolitan bishop with the right of election throughout the province was thus reaffirmed, in accordance with Canon 4 of Nicaea.

53 Регламентация положения епископа столицы была связана как раз с тем, что он совершал рукоположения малоазийских епископов в обход митрополитов соответствующих провинций.

54 Обсуждение дела Фотия Беритского очевидным образом повлияло и на формулировку ряда других канонов Халкидонского собора: к примеру, 9-го, 17-го и 28-го. Ср.: [Leuenberger-Wenger, 2019, p. 309-310].

$55 \mathrm{C}$ этой целью Собор принимает также канон 25-й, согласно которому рукоположение епископа должно было совершаться митрополитом, и устанавливает предельный срок в три месяца для совершения рукоположения [Schwartz, 1931, 162.28-32]. Этот канон очевидным образом развивает 4-е никейское правило, согласно которому митрополит лишь утверждал рукоположение епископа.

${ }^{56}$ Ср. подтверждение императорами административных прав Никомидии как столицы провинции при даровании статуса митрополии другим городам провинции Вифиния - Никее и Халкидону [Schwartz, 1931, 157.34-38; Schwartz, 1935, 61.1-17]. О древнем митрополичьем статусе Никомидии: [Robert, 1977]. Впрочем, при разделе провинции епископ города, получившего статус митрополии (столицы) новой провинции, автоматически получал и права рукоположения в ней. Ср. казус с разделением Каппадокии на Каппадокию Первую и Вторую в бытность Василия Великого митрополитом Кесарии Каппадокийской [Van Dam, 2002, p. 28-38]. 
3. Грацианский М.В. 2008. Евстафий, еп. Беритский. Православная энциклопедия, т. 17, М., ЦНЦ «Православная энциклопедия», 302-303.

4. Грацианский М.В. 2019. Четвертый Вселенский собор и проблема первенства римского епископа. Вестник Волгоградского государственного университета. Серия 4: История. Регионоведение. Международные отношения, 24.6: 255-271.

5. Кофанов Л.Л. 2012. К интерпретации понятия praeiudicium в римском праве. Вестник НГУ. Серия: Право, 9.1: 5-14.

6. Норкин К.В. 2019. Становление церковного первенства Арля в Галлии и римские папы (398-432 гг.). Византийский временник, 103: 53-69.

7. Пашков Д.В. 2018. Процедура Вселенских Соборов. Собор и соборность: к столетию начала новой эпохи. Материалы международной научной конференции 13-16 ноября 2017 г. М., $27-39$.

8. Троицкий С.В. 1961. О смысле 9-го и 17-го канонов Халкидонского Собора. Журнал Московской патриархии, 2: 57-65.

9. Троицкий С.В. 1959. Халкидонский Собор и восточный папизм. Вестник русского западно-европейского патриаршего экзархата, 32: 255-268.

10. Aliquot J. 2011. Les Tyriens dans le monde romain, d'Auguste à Dioclétien. P.-L. Gatier, J. Aliquot, L. Nordiguian (eds.). Sources de l'histoire de Tyr. Textes de l'Antiquité et du Moyen Âge. Beyrouth, Presses de l'Ifpo, Presses de l'Université Saint-Joseph, 73-115.

11. Bevan G.A., Gray P.T.R. 2008. The Trial of Eutyches: A New Interpretation. Byzantinische Zeitschrift, 101: 617-657.

12. Butcher K. 2003. Roman Syria and the Near East. London, The British Museum Press, 472.

13. Chrysos E. 1979. Konzilspräsident und Konzilsvorstand. Annuarium Historiae Conciliorum, 11: 1-17.

14. Draguet R. 1931. La christologie d'Eutychès d'après les actes du synode de Flavien (448). Byzantion, 6: 441-457.

15. Haensch R. 1997. Capita Provinciarum: Statthaltersitze und Provinzialverwaltung in der römischen Kaiserzeit. Mainz, P. von Zabern, 863.

16. Haensch R. 2006. Provinzhauptstädte als «religiöse Zentren»? Die Situation in Kaiserzeit und Spätantike. H. Cancik, A. Schäfer, W. Spickermann (eds.). Zentralität und Religion. Tübingen, Mohr Siebeck, 125-144. VI, 545.

17. Jones A.H.M. 1964. The Later Roman Empire 284-602. Vol. 2. Oxford: Basil Blackwell,

18. Jones Hall L. 2001-2002. Berytus through the Classical Texts: from Colonia to Civitas. ARAM, 13-14: 141-169.

19. Jones Hall L. 2004. Roman Berytus. Beirut in Late Antiquity. London, New York, Routledge, XXIII, 372.

20. Jones A.H.M. 1971. The Cities of the Eastern Roman Provinces. Oxford: The Clarendon Press, xvii, 595.

21. Krueger P. (ed.) 1954. Corpus iuris civilis. Vol. 2: Codex Iustinianus. Berlin, apud Weidemannos, XXVIII, 513.

22. Leuenberger-Wenger S. 2019. Das Konzil von Chalcedon und die Kirche. Konflikte und Normierungsprozesse im 5. und 6. Jahrhundert [Supplements to Vigiliae Christianae, 153]. Leiden, Boston, Brill, XVII, 617.

23. May G. 1989. Das Lehrverfahren gegen Eutyches im November des Jahres 448. Zur Vorgeschichte des Konzils von Chalkedon. Annuarium historiae Conciliorum, 21: 1-61.

24. Millar F. 2012. Tyre and Berytus in the Mid-Fifth Century: Metropolitan Status and Ecclesiastical Hierarchy. Scripta Classica Israelitica, 33: 65-84.

25. Munier C. (ed.) 1963. Concilia Galliae a. 314 - a. 506. (Corpus Christianorum. Series Latina, 148). Turnhout, Brepols, XI, 285.

26. Ohme H. 1998. Kanon ekklesiastikos. Die Bedeutung des altkirchlichen Kanonbegriffs. Berlin, New York, Walter de Gruyter, XVII, 666.

27. Price R. 2009. Presidency and Procedure at the Early Ecumenical Councils. Annuarium Historiae Conciliorum, 41: 241-274.

28. Puech, B. 2004. Des cités-mères aux métropoles. S. Follert (ed.). L'Hellénisme d'époque romaine: nouveaux documents, nouvelles approches ( ${ }^{\text {er }}$ s. a.C $-\mathrm{III}^{\mathrm{e}}$ s. p.c.). Paris, 357-404. 
29. Rammelt C. 2008. Ibas von Edessa. Rekonstruktion einer Biographie und dogmatischen Position zwischen den Fronten [Arbeiten zur Kirchengeschichte, 106]. Berlin, New York, Walter de Gruyter, X, 344.

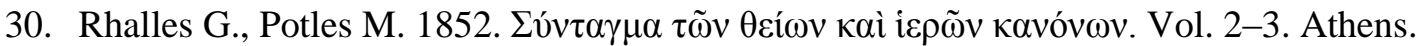

31. Robert L. 1977. La Titulature de Nicée et de Nicomédie: La Gloire et la haine. Harvard Studies in Classical Philology, 81: 1-39.

32. Schwartz E. (ed.). 1933. Acta conciliorum oecumenicorum. T. II. Vol. 1. Pars 2. Berlin, Leipzig, Walter de Gruyter, XII, 163.

33. Schwartz E. (ed.). 1935. Acta conciliorum oecumenicorum. T. II. Vol. 1. Pars 3. Berlin, Leipzig, Walter de Gruyter, XXX, 154.

34. Schwartz E. 1921. Über die Reichskonzilien von Theodosius bis Justinian. Zeitschrift der Savigny-Stiftung für Rechtsgeschichte. Kanonistische Abteilung, 42: 231-234.

35. Schwartz E. 1929. Der Prozeß des Eutyches. Sitzungsberichte der Bayerischen Akademie der Wissenschaften. Philologisch-historische Abteilung. Heft 5. München, 1-93.

36. Smith M.S. 2018. The Idea of Nicaea in the Early Church Councils, AD 431-451. Oxford, Oxford University Press, XIII, 230.

37. Troianos S. 2017. Die Quellen des byzantinischen Rechts. Berlin, Boston, Walter de Gruyter, XIX, 407.

38. Van Dam R. 2002. Kingdom of Snow: Roman Rule and Greek Culture in Cappadocia. Philadelphia: University of Pennsylvania Press, IX, 290

39. Van Roey A. 1967. Eustathius. Dictionnaire d'histoire et de géographie Ecclésiastiques, 16: 23.

40. Vitale M. 2013. Koinon Syrias: Priester, Gymnasiarchen und Metropoleis der Eparchien im Kaiserzeitlichen Syrien. Berlin: Akademie Verlag, 196.

41. Vranić V. 2008. The Christology of Eutyches at the Council of Constantinople in 448. Philotheos, 8: 208-221.

42. Windau B. 2002. Eustathius von Berytus. Lexikon der antiken christlichen Literatur. Freiburg im Breisgau, 250.

\section{References}

1. Vselenskie sobory [Ecumenical Councils]. 2005. Moscow, CSC «Pravoslavnaia entsiklopediia», 223 (in Russian).

2. Gratsianskiy M.V. 2007. Domn II, ep. Antiokhiiskii [Domnus II, Bishop of Antioch]. Pravoslavnaia entsiklopediia [Orthodox Encyclopedia], vol. 15, Moscow, CSC «Pravoslavnaia entsiklopediia», 630-632 (in Russian).

3. Gratsianskiy M.V. 2008. Evstafii, ep. Beritskii [Eustathius, Bishop of Berytus]. Pravoslavnaia entsiklopediia [Orthodox Encyclopedia], vol. 17, Moscow, CSC «Pravoslavnaia entsiklopediia», 302-303 (in Russian).

4. Gratsianskiy M.V. 2019. Chetvertyi Vselenskii sobor i problema pervenstva rimskogo episkopa [The Fourth Ecumenical Council and the Issue of the Primacy of the Bishop of Rome]. Vestnik Volgogradskogo gosudarstvennogo universiteta [Bulletin of Volgograd State University]. Seriia 4: Istoriia. Regionovedenie. Mezhdunarodnye otnosheniia, 24.6: 255-271 (in Russian).

5. Kofanov L.L. 2012. K interpretatsii poniatiia praeiudicium v rimskom prave [About the Interpretation of 'Praeiudicium' Concept in Roman Law]. Vestnik Novosibirskogo gosudarstvennogo universiteta [Bulletin of NSU]. Seriia: Pravo, 9.1: 5-14 (in Russian).

6. Norkin K.V. 2019. Stanovlenie tserkovnogo pervenstva Arlia v Gallii i rimskie papy (398-432 gg.) [The Formation of the Ecclesiastical Primacy of Arles in Gaul and the Popes of Rome in 398-432]. Vizantiiskii vremennik [Byzantine temporary], 103: 53-69 (in Russian).

7. Pashkov D.V. 2018. Protsedura Vselenskikh Soborov [The Procedure of the Ecumenical Councils]. Sobor i sobornost': k stoletiiu nachala novoi epokhi. Materialy mezhdunarodnoi nauchnoi konferentsii 13-16 nojabria $2017 \mathrm{~g}$. [Synod and collegiality: the centenary of the beginning of a new era. Materials of the international scientific conference, november 13-16, 2017] Moscow, 27-39 (in Russian).

8. Troitskii S.V. 1961. O smysle 9-go i 17-go kanonov Khalkidonskogo Sobora [About the Sense of the $19^{\text {th }}$ and th $17^{\text {th }}$ Canons of the Council of Chalcedon]. Zhurnal Moskovskoi patriarkhii [Journal of the Moscow Patriarchate], 2: 57-65 (in Russian). 
9. Troitskii S.V. 1959. Khalkidonskii Sobor i vostochnyi papizm [The Council of Chalcedon and the Eastern Papism]. Vestnik russkogo zapadno-evropeiskogo patriarshego ekzarkhata [Bulletin of the Russian West European Patriarchal Exarchate], 32: 255-268 (in Russian).

10. Aliquot J. 2011. Les Tyriens dans le monde romain, d'Auguste à Dioclétien. P.-L. Gatier, J. Aliquot, L. Nordiguian (eds.). Sources de l'histoire de Tyr. Textes de l'Antiquité et du Moyen Âge. Beyrouth, Presses de l'Ifpo, Presses de l’Université Saint-Joseph, 73-115.

11. Bevan G.A., Gray P.T.R. 2008. The Trial of Eutyches: A New Interpretation. Byzantinische Zeitschrift, 101: 617-657.

12. Butcher K. 2003. Roman Syria and the Near East. London, The British Museum Press, 472. 11: $1-17$.

13. Chrysos E. 1979. Konzilspräsident und Konzilsvorstand. Annuarium Historiae Conciliorum,

14. Draguet R. 1931. La christologie d'Eutychès d'après les actes du synode de Flavien (448). Byzantion, 6: 441-457.

15. Haensch R. 1997. Capita Provinciarum: Statthaltersitze und Provinzialverwaltung in der römischen Kaiserzeit. Mainz, P. von Zabern, 863.

16. Haensch R. 2006. Provinzhauptstädte als «religiöse Zentren»? Die Situation in Kaiserzeit und Spätantike. H. Cancik, A. Schäfer, W. Spickermann (eds.). Zentralität und Religion. Tübingen, Mohr Siebeck, 125-144. VI, 545

17. Jones A.H.M. 1964. The Later Roman Empire 284-602. Vol. 2. Oxford: Basil Blackwell,

18. Jones Hall L. 2001-2002. Berytus through the Classical Texts: from Colonia to Civitas. ARAM, 13-14: 141-169.

19. Jones Hall L. 2004. Roman Berytus. Beirut in Late Antiquity. London, New York, Routledge, XXIII, 372.

20. Jones A.H.M. 1971. The Cities of the Eastern Roman Provinces. Oxford: The Clarendon Press, xvii, 595.

21. Krueger P. (ed.) 1954. Corpus iuris civilis. Vol. 2: Codex Iustinianus. Berlin, apud Weidemannos, XXVIII, 513.

22. Leuenberger-Wenger S. 2019. Das Konzil von Chalcedon und die Kirche. Konflikte und Normierungsprozesse im 5. und 6. Jahrhundert [Supplements to Vigiliae Christianae, 153]. Leiden, Boston, Brill, XVII, 617.

23. May G. 1989. Das Lehrverfahren gegen Eutyches im November des Jahres 448. Zur Vorgeschichte des Konzils von Chalkedon. Annuarium historiae Conciliorum, 21: 1-61.

24. Millar F. 2012. Tyre and Berytus in the Mid-Fifth Century: Metropolitan Status and Ecclesiastical Hierarchy. Scripta Classica Israelitica, 33: 65-84.

25. Munier C. (ed.) 1963. Concilia Galliae a. 314 - a. 506. (Corpus Christianorum. Series Latina, 148). Turnhout, Brepols, XI, 285.

26. Ohme H. 1998. Kanon ekklesiastikos. Die Bedeutung des altkirchlichen Kanonbegriffs. Berlin, New York, Walter de Gruyter, XVII, 666.

27. Price R. 2009. Presidency and Procedure at the Early Ecumenical Councils. Annuarium Historiae Conciliorum, 41: 241-274.

28. Puech, B. 2004. Des cités-mères aux métropoles. S. Follert (ed.). L'Hellénisme d'époque romaine: nouveaux documents, nouvelles approches (Ier s. a.C - IIIe s. p.c.). Paris, 357-404.

29. Rammelt C. 2008. Ibas von Edessa. Rekonstruktion einer Biographie und dogmatischen Position zwischen den Fronten [Arbeiten zur Kirchengeschichte, 106]. Berlin, New York, Walter de Gruyter, X, 344.

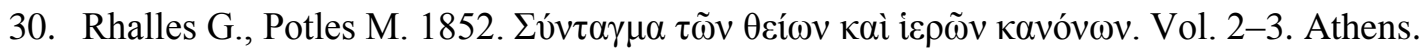

31. Robert L. 1977. La Titulature de Nicée et de Nicomédie: La Gloire et la haine. Harvard Studies in Classical Philology, 81: 1-39.

32. Schwartz E. (ed.). 1933. Acta conciliorum oecumenicorum. T. II. Vol. 1. Pars 2. Berlin, Leipzig, Walter de Gruyter, XII, 163.

33. Schwartz E. (ed.). 1935. Acta conciliorum oecumenicorum. T. II. Vol. 1. Pars 3. Berlin, Leipzig, Walter de Gruyter, XXX, 154.

34. Schwartz E. 1921. Über die Reichskonzilien von Theodosius bis Justinian. Zeitschrift der Savigny-Stiftung für Rechtsgeschichte. Kanonistische Abteilung, 42: 231-234. 
35. Schwartz E. 1929. Der Prozeß des Eutyches. Sitzungsberichte der Bayerischen Akademie der Wissenschaften. Philologisch-historische Abteilung. Heft 5. München, 1-93.

36. Smith M.S. 2018. The Idea of Nicaea in the Early Church Councils, AD 431-451. Oxford, Oxford University Press, XIII, 230.

37. Troianos S. 2017. Die Quellen des byzantinischen Rechts. Berlin, Boston, Walter de Gruyter, XIX, 407.

38. Van Dam R. 2002. Kingdom of Snow: Roman Rule and Greek Culture in Cappadocia. Philadelphia: University of Pennsylvania Press, IX, 290

39. Van Roey A. 1967. Eustathius. Dictionnaire d'histoire et de géographie Ecclésiastiques, 16: 23.

40. Vitale M. 2013. Koinon Syrias: Priester, Gymnasiarchen und Metropoleis der Eparchien im Kaiserzeitlichen Syrien. Berlin: Akademie Verlag, 196.

41. Vranić V. 2008. The Christology of Eutyches at the Council of Constantinople in 448. Philotheos, 8: 208-221.

42. Windau B. 2002. Eustathius von Berytus. Lexikon der antiken christlichen Literatur. Freiburg im Breisgau, 250.

\section{ИНФОРМАЦИЯ ОБ АВТОРЕ}

Грацианский Михаил Вячеславович, кандидат исторических наук, ведущий научный сотрудник Лаборатории по изучению стран Причерноморья и Византии в средние века исторического факультета Московского государственного университета имени М.В. Ломоносова, г. Москва, Россия

\section{INFORMATION ABOUT THE AUTHOR}

Mikhail V. Gratsianskiy, candidate of Sciences (History), $\mathrm{PhD}$, leading researcher of the Center of Byzantine and the Black Sea Region Studies of the Faculty of History of Lomonosov Moscow State University, Moscow, Russia 